\title{
Mesoporous Molecular Sieves MCM-41 with a Hollow Tubular Morphology
}

\author{
Hong-Ping Lin, Soofin Cheng, and Chung-Yuan Mou* \\ Department of Chemistry, National Taiwan University, Taipe, Taiwan 106, R.O.C. \\ Received August 19, 1997. Revised Manuscript Received November 6, 1997
}

\begin{abstract}
The synthesis of the MCM-41 materials with novel hollow tubular morphology in high alkaline condition was studied in detail. The tubular structure can be obtained in a narrow range of water/ $\mathrm{C}_{16} \mathrm{TMAB}$ molar ratio, in which lamellar membranes consisting of the hexagonal arrangement of rod micelles exist. Tubular structures result from a membraneto-tubules transformation. Adding a proper amount of salts into the synthesis gel of higher water/ $\mathrm{C}_{16} \mathrm{TMAB}$ molar ratio can hel p forming tubular structure. Temperature of the reaction system has to be controlled near $30^{\circ} \mathrm{C}$ in order to obtain the tubular MCM-41. Incorporation of aluminum into the framework affects the morphology and crystallinity of resultant MCM41 products. But the stirring rate does not have an appreciable effect on the formation of tubular morphology. The sample synthesized with the $\mathrm{C}_{16} \mathrm{TMACl}-$ silicate system with a suitable water content leads to about $70 \%$ in tubular morphology, and the hexagonal structure of MCM-41 channels was formed from a lamellar intermediate. Surfactants with shorter carbon chain length $(n<16)$ would inhibit the formation of tubular morphology. The product of the $C_{12} T M A B$-silicate system was in particulate form and that of $C_{14} T M A B$-silicate in broken tubular morphology.
\end{abstract}

\section{Introduction}

Recently, the discovery of the new family of crystalline mesoporous materials M 41S by researchers at Mobil Oil Corp. ${ }^{1,2}$ has attracted the attention of many scientists. These mesoporous molecular si eves with adjustable and uniformed pore sizes in the range 1.5-10.0 nm cover a new range of potential applications. One member of this series, MCM-41, which possesses a hexagonal arrangement of uniformly sized channel mesopores, has been the focus of most recent investigations as catalysts support and advanced materials. ${ }^{3-10}$

Up to now, many reports concerning the synthesis of MCM-41 materials are concentrated on improving the synthetic procedures in order to obtain MCM-41 materials of high thermal stability and to understand the formation mechanism. ${ }^{11-16}$ Most of the morphology of

* E-mail: cymou@cc.ntu.edu.tw. Fax: 886-2-3636359.

(1) Kresge, C. T.; Leonowic, M. E.; Roth, W. J .; Vartuli, J . C.; Beck, J. S. Nature 1992, 359, 710 .

(2) Beck, J. S.; Vartuli, J . C.; Roth, W. J .; Leonowicz, M. E.; Kresge, C. T.; Schmitt, K. D.; Chu, C. T.-W.; Olson, D. H.; Sheppard, E. W. Higgins, S. B.; Schlenker, J . L. J . Am. Chem. Soc. 1992, 114, 10834.

(3) Sayari, A. Chem. Mater. 1996, 8, 1840.

(4) Neumann, R.; Khenkin, K. Chem. Commun. 1996, 23, 2643.

(5) Chakraborty, B.; Pulikottil, A. C.; Viswanathan, B. Catal. Lett. 1996, 39, 63 .

(6) Hartmann, M.; Popll, A.; Kenvan, L. J . Phys. Chem. 1996, 100, $0,9906$.

(7) Reddy, J. S.; Sayari, A. J . Chem. Soc., Chem. Commun. 1995, 2231.

(8) Wu, C.-G.; Bein, T. Science 1994, 264, 1757.

(9) Wu, C.-G.; Bein, T. Science 1994, 266, 1013.

(10) Lee, Y. S.; Surjadi, D.; Rathman, J. F. Langmuir 1996, 12 6202. (b) Ko, C. H.; Ryoo, R. J . Chem. Soc., Chem. Commun. 1996, 2467.

(11) Monnier, A.; Schüth, F.; Huo, Q.; Kumar, D.; Margolese, D.; Maxwell, R. S.; Stucky, G. D.; Krishnamurty, M.; Petroff, P.; Firouzi A.; J anicke, M.; Chmelka, B. F. Science 1993, 261, 1299.
MCM-41 material reported in the literature was in microparticles. This may be due to the fact that the silicate structures, prepared from acidified silicate or highly condensed silicate, are too rigid to transform into other morphologies. Recently, several research groups showed that the surfactant/silicate systems can show a more complex organization of hierarchical order by varying the gel and interface composition during synthesis. ${ }^{17-25}$ The cal cined products of MCM-41 show a rich variety of morphologies dependent on the syn-

(12) Firouzi, A.; Kumar, D.; Besier, T.; Sieger, P.; Huo, Q.; Walker S. A.; Zasadzinski, J . A.; Glinka, C.; Nicol, J .; Margolese, D.; Stucky, G. D.: Chmelka, B. F. Science 1995, 267, 1138.

(13) Huo, Q.; Margolese, D. I.; Ciesla, U.; Demuth, D. G.; Feng, P.; Gier, T. E.; Sieger, P.; Firouzi, A.; Chmelka, B. F.; Schüth, F.; Stucky, G. D. Chem. Mater. 1994, 6, 1176.

(14) Fyfe, C. A.; Fu, G. J . Am. Chem. Soc. 1995, 117, 9709. 1147.

(16) Cheng, C. F.; Park, D. H.; Klinowski, J . J . Chem. Soc., Faraday Trans. 1997, 93, 193

(17) Schacht, S.; Hou, Q.; Voigtmartin, I. G.; Stucky, G. D.; Schüth, F. Science 1996, 273, 768

(18) Mann S.; Ozin, G. A. Nature 1996, 382, 313. (b) Yang, H.; Coombs, N.; Sokolov, I.; Ozin, G. A. Nature 1996, 381, 589.

(19) Tanev, P. T.; Pinnavaia, T. J . Science 1996, 271, 1267. (b) Tanev, P. T.; Y. Liang; Pinnavaia, T. J . J . Am. Chem. Soc. 1997, 119, 8616.

(20) Grün, M.; Lauer, I.; Unger, K. K. Adv. Mater. 1997, 9, 254

(21) Hou, Q. H.; Feng, J .; Schüth, F.; Stucky, G. D. Chem. Mater. 1997, 9, 14

(22) Yang, H.; Coombs, N.; Ozin, G. A. Nature 1997, 386, 692. (b) Ozin, G. A.; Yang, H.; Sokolov, I.; Coombs, N. Adv. Mater. 1997, 9 , 662

(23) Mann, S.; Ozin, G. A. Nature 1996, 382, 313.

(24) Aksay, I. A.; Trau, M.; Mann, S.; Honma, I.; Yao, N.; Zhou, L.; Fenter, P.; Eisenberger, P. M.; Gruner, S. M. Science 1996, 273, 892. (b) McGrath, K. M.; Dabbs, D. M.; Yao, N.; Aksay, I. A.; Gruner, S. M. Science 1997, 277, 552.

(25) Davis, S. A.; Burkett, S. L.; Mendelson, N. H.; Mann, S. Nature $1997,385,420$. 


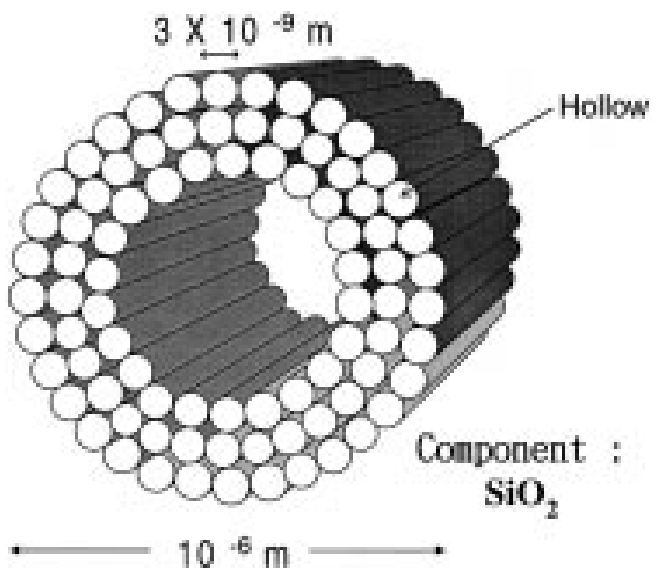

Figure 1. Schematic diagram of the mesoporous molecular sieve MCM-41 with hierarchical hollow tubule structure.

thetic strategy. Using oil/solution microemulsion as templates, Schacht et al. showed that the ordered mesopores silica can form macroscopically hollow spherical, fibrous morphology, or thin sheet with careful control of the oil/water interface in the microemulsion. ${ }^{17}$ Ozin and co-workers have described an oriented mesoporous silica films grown on the mica-water or airwater interfaces. ${ }^{18}$ They further obtained a rich diversity of morphology of mesoporous silica, ropes, discoids, and wheels among others. ${ }^{22}$ Tanev et al. described a synthetic strategy using multilamella vesicles as templates to form hollow mesoporous silica. ${ }^{19}$ These rich morphologies are obtained from the complex interplay of curvature changes in the meso structures of the gels and silica condensations. Thus, although the morphology of MCM-41 material is not necessary in microparticles, it might be varied by using suitable interfaces, reaction compositions, and synthetic procedure. But most of these hierarchical structures are synthesized under acidic conditions through weak hydrogen-bonding forces for persevering the large-scale morphology. In strongly alkaline conditions, it was thought that the interactions between silicate anions and cationic surfactants are too strong to create the large micron-sized hierarchical structure.

In our previous report, ${ }^{26}$ we showed that an ordered mesoporous molecular sieve MCM-41 with a hollow tubules-within-a-tubule hierarchical structure (Figure 1) could be successfully synthesized in a highly alkaline condition by careful control of the surfactant-water content and the silica condensation rate. Figure 1 shows a schematic description of the tubular structure. It is a hollow tubule with coaxial cylindrical nanometer channels of MCM-41 constituting the wall of the tubule. There are two length scales in this self-similar hierarchical order: micrometer for the big tubule and nanometer for the small channels. Both sizes can be controlled to a certain extent as will be shown later in this paper. This hierarchically ordered structure of $\mathrm{C}_{16} \mathrm{TMAB}-$ aluminosilicate system was proposed to take place through a liquid-crystal phase transformation under a gradual neutralization process. A soft intermediate with a proper length scale was necessary for the production of the tubular structure. Because the microtubular morphology of MCM-41 products is new, the

(26) Lin, H. P.; Mou, C. Y. Science 1996, 273, 765. factors affecting the formation of this new morphology need to be examined carefully. In this paper, crucial factors that control the formation of MCM-41 materials in tubular structure are investigated, including the water/surfactant ratio, the addition of salts, the Si/Al ratio, reaction temperature, stirring rate, the carbon chain length, and counterion of the surfactant.

Our synthetic method, a delayed neutralization scheme, ${ }^{27}$ is based on the consideration of temporal separation of self-assembly of surfactant-silicate and silica condensation. As recently discussed by Stucky et al., ${ }^{15}$ there are two types of molecular interactions operating in the complex solution during synthesis: ionic interactions between surfactant and silicate ions, and the chemical force of silica condensation. If one starts the synthesis at high alkalinity, one has the opportunity of forming soft and deformable surfactant/ silicate assemblies first. The delayed neutralization process is then a way to control the subsequent structure transformation in larger scale $(\sim \mu \mathrm{m})$ while solidifying the whole materials. In this paper, we will further explore the controlling factors in this complex structure formation.

\section{Experiment}

Materials. Thesilica source was sodium silicate $\left(27 \% \mathrm{SiO}_{2}\right.$, $14 \% \mathrm{NaOH}$ ) from Aldrich. The quaternary ammonium surfactant compounds were obtained from Aldrich or Merck without further purification. They were cetyltrimethylammonium bromide ( $\left.\mathrm{C}_{16} \mathrm{TM} A \mathrm{~B}\right)$, cetyltrimethylammonium chl oride $\left(\mathrm{C}_{16} \mathrm{TMACl}\right)$, myristyltrimethylammonium bromide $\left(\mathrm{C}_{14} \mathrm{TM} A B\right)$, and dodecyltrimethylammonium bromide $\left(C_{12} T M A B\right)$. The source of aluminum was sodium aluminate and aluminum sulfate from Riede-de Haën and Sigma. Sulfuric acid was from Merck.

Synthesis. To prepare pure-silica MCM-41 materials, sodium silicate was added to a clear aqueous solution of the surfactant under stirring and a gel mixture was formed. After stirring for about $10 \mathrm{~min}$ at room temperature, a proper amount of $1.20 \mathrm{M}$ sulfuric acid or other acids was added slowly into the gel mixture with a pipet. This step takes up to 30 min. The $\mathrm{pH}$ value of the final mixture was adjusted to about 10. The molar ratio of the resultant gel was $1 \mathrm{SiO}_{2}: 0.48$ surfactant:0.39 Na2 $\mathrm{O}: 0.29 \mathrm{H}_{2} \mathrm{SO}_{4}: \mathrm{xH}_{2} \mathrm{O}$, where the value of $x$ was in the range $50-100$ depending on the surfactant used. After stirring for $20 \mathrm{~min}$, the mixture was loaded into an autoclave and statically heated at $100{ }^{\circ} \mathrm{C}$ for $48 \mathrm{~h}$. The resultant solid products were recovered by filtration, washing with deionized water and drying in air at room temperature or at $100{ }^{\circ} \mathrm{C}$. To remove the organic species in the pores of MCM-41, the as-synthesized samples were calcined in air at $560{ }^{\circ} \mathrm{C}$ for $6 \mathrm{~h}$ (heated from room temperature to $560{ }^{\circ} \mathrm{C}$ with a heating rate of $\left.1.5^{\circ} \mathrm{C} / \mathrm{min}\right) . .^{27}$

The aluminosilicate MCM-41 was synthesized with the same processes described above except that a suitable amount of sodium aluminate was added into the solution of surfactant in the first step.

Characterization. Powder X-ray diffraction (XRD) data were collected on a Scintag X1 diffractometer using $\mathrm{Cu} \mathrm{K \alpha}$ radiation $(\lambda=0.154 \mathrm{~nm})$. The transmission electron micrographs (TEM) were taken on a Hitachi H-7100 operated at $100 \mathrm{keV}$. Scanning electron mi croscopy (SEM) was performed on a Hitachi S-2400 or S-800 using an accelerating voltage of $20 \mathrm{keV}$. The $\mathrm{N}_{2}$ adsorption-desorption isotherms were obtained at $77 \mathrm{~K}$ on a Micrometric ASAP 2000 apparatus. The sample was outgassed at $300{ }^{\circ} \mathrm{C}$ for about $6 \mathrm{~h}$ in $10^{-3} \mathrm{Torr}$ prior to adsorption. The data were analyzed by the $\mathrm{BJ} \mathrm{H}$

(27) Lin, H. P.; Cheng, S.; Mou, C. Y. Microporous Mater. 1997 10,111 


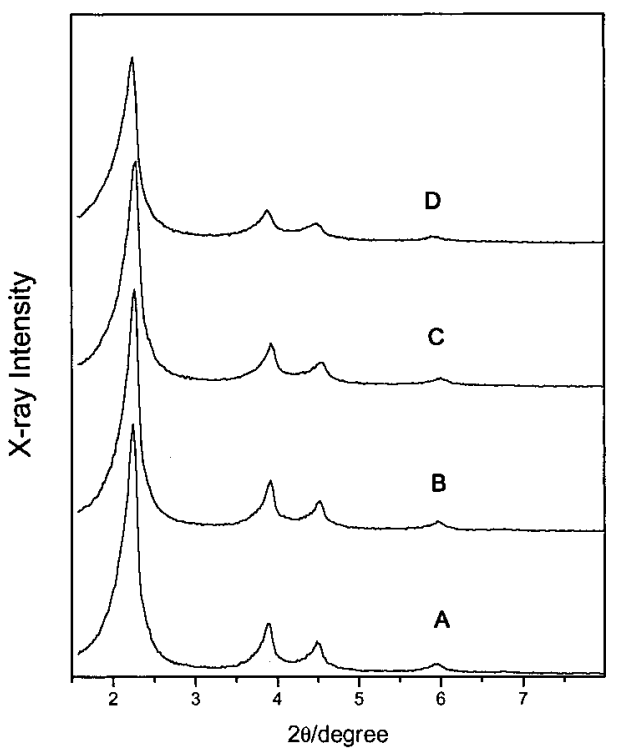

Figure 2. Powder $\mathrm{X}$-ray diffraction patterns of the $\mathrm{MCM}-41$ materials prepared from $\mathrm{C}_{16} \mathrm{TMAB}$-aluminosilicate system with different water content. The mole ratio of the gel $1 \mathrm{SiO}_{2}$ : $0.014 \mathrm{Al}_{2} \mathrm{O}_{3}: 0.39 \mathrm{Na}_{2} \mathrm{O}: 0.48 \mathrm{C}_{16} \mathrm{TAB}: 0.29 \mathrm{H}_{2} \mathrm{SO}_{4}: \mathrm{x} \mathrm{H}_{2} \mathrm{O}$. (A) $\mathrm{x}$ $=90.6$, (B) $x=83.56$, (C) $x=81.0$, (D) $x=73.0$.

(Barrett-J oyner-Halenda) method with the Halsey equation for multilayer thickness. The pore size distribution curve was obtained from the analysis of the desorption portion of the isotherm. The solid-state ${ }^{27} \mathrm{Al}$ MAS NMR experiments were performed at room temperature on a Bruker MSL 500 NMR with a magnetic field of $11 \mathrm{~T}$.

\section{Results}

Water/Surfactant Ratio. To investigate the effect of water content on the morphology of $\mathrm{C}_{16} \mathrm{TMAB}-$ al uminosilicate system, the water/surfactant ratio was first varied. Figure 2 shows four XRD patterns of the MCM-41 products obtained from four reaction mixtures with different water contents. Since strong electrostatic interaction between cationic surfactants and silicate anionic species is the main determining factor in the formation of hexagonal structure formation of MCM41, the water content does not have a apparent influence on the nanometer structure order of the MCM-41 materials as showed in Figure 2. Indeed, it has been previously reported that the MCM-41 could be synthesized with the surfactant concentration as low as the critical micelle concentration. ${ }^{28}$

Nevertheless, the scanning electron micrographs (SEM) of the as-synthesized samples (Figure 3) corresponding to the samples in Figure 2 reveal that the morphologies are very different. The tubular structure of MCM-41 products can only be fabricated in a narrow range of water content $\left(\mathrm{H}_{2} \mathrm{O} / \mathrm{SiO}_{2}\right.$ about $\left.80-85\right)$. Beyond this range, the formation of the tubular structure is inhibited, and the morphology of the MCM-41 materials is only in microparticles. The effect of water/surfactant ratio is also examined by varying the surfactant concentration, it was found that the new tubular structure of MCM-41 materials could only be formed in a narrow range of water/surfactant ratio (about 180-165). When the water/surfactant ratio is higher than 180 , one cannot obtain the tubule structure. Also, a decrease in water/

(28) Cheng, C. F.; Luan Z.; Klinowski, J . Langmuir 1995, 11, 2815. surfactant ratio would lead to a reaction system of high viscosity and few tubular structure was formed. We previously proposed that the tubular morphology of MCM-41 is formed from a mixed lamellar-hexagonal intermediate where soft membranes consisting of hexagonally arranged rod micelles are separated by water layers. Then, an instability of membrane-to-tubule transformation can be induced by acidification. We proposed $^{26}$ that layered structures are stabilized by the electrostatic and entropy undulation repulsion force between the membrane layers. ${ }^{29}$ Both are critically dependent on the thickness of the water layer. Too little water will lead to a strong attractive force between layers, and the membrane will be difficult to bend. On the other hand, too much water between layers could not maintain the stability of the mixed layers and it would just fall apart. Thus, such intermediate structure would be expected to depend critically on the osmotic pressure of the water layers. This may explain why the water/surfactant ratio range is so narrow for the stability of the intermediate membrane structure.

In Figure 3B,C, we found that the diameters of the tubules were about $0.52 \mu \mathrm{m}$ at the surfactant/water ratio of 174 and $0.25 \mu \mathrm{m}$ at the surfactant/water ratio of 169 . This indicates that the size of the tubular structure of MCM-41 materials prepared from $\mathrm{C}_{16} \mathrm{TMAB}$-aluminosilicate is adjustable and decreases with the water/ surfactant ratio.

To investigate the thermal and hydrothermal stability, the calcined MCM-41 samples with tubular structure were heated at $900{ }^{\circ} \mathrm{C}$ in air for $6 \mathrm{~h}$ and immersed in boiling water for $14 \mathrm{~h}$. From the results of XRD and $\mathrm{N}_{2}$ adsorption-desorption isotherm, the samples show only about $0.3-0.4 \mathrm{~nm}$ lattice shrinkage and preserved the hexagonal mesoporous structure. This shows that the nanosized structures of these tubular MCM-41 products have both high thermal and hydrothermal stability. ${ }^{30}$ And moreover, the tubular morphology of these samples identified by SEM were almost as same as that of the as-synthesized one. It shows that the hierarchical micron-sized tubules have also high hydrothermal and thermal stability.

Addition of Salts. With the composition of high water/surfactant ratio set at 189 , the gel has less tendency to form the membrane layer of the surfactant and the morphology of the MCM-41 materials thus obtained is only in microparticle form. Salts have the shielding effect to reduce the electrostatic repulsion between the headgroups of the surfactants and thus promote the hexagonal-to-lamellar transition. ${ }^{31,32} \mathrm{We}$ can expect that adding salts would help forming the mixed hexagonal/lamellar phase necessary for the tubular structure. $\mathrm{KNO}_{3}$ or $\mathrm{NaBr}$ was added into this high water/surfactant ratio system, and the morphology of the MCM-41 products changes from mi croparticle to tubular structure as shown in Figure 4A,B. Other electrolytes, such as $\mathrm{NaCl}, \mathrm{K}_{2} \mathrm{SO}_{4}, \mathrm{Na}_{2} \mathrm{SO}_{3}$, or $\mathrm{CH}_{3-}$ COONa examined under the same reaction composition of high $\mathrm{H}_{2} \mathrm{O}$ /surfactant, also have the effect to promote

(29) Helfrich, W. Z. Naturforsch 1978, 33a, 305.

(30) Ryoo, R.; J un, S. J . Phys. Chem. B 1997, 101, 317.

(31) Tanford, C. The Hydrophobic Effect; Wiley: New York, 1973.

(32) Evans, D. F.; Wennerström, H. The Colloidal Domain; VHC: New York, 1994. 

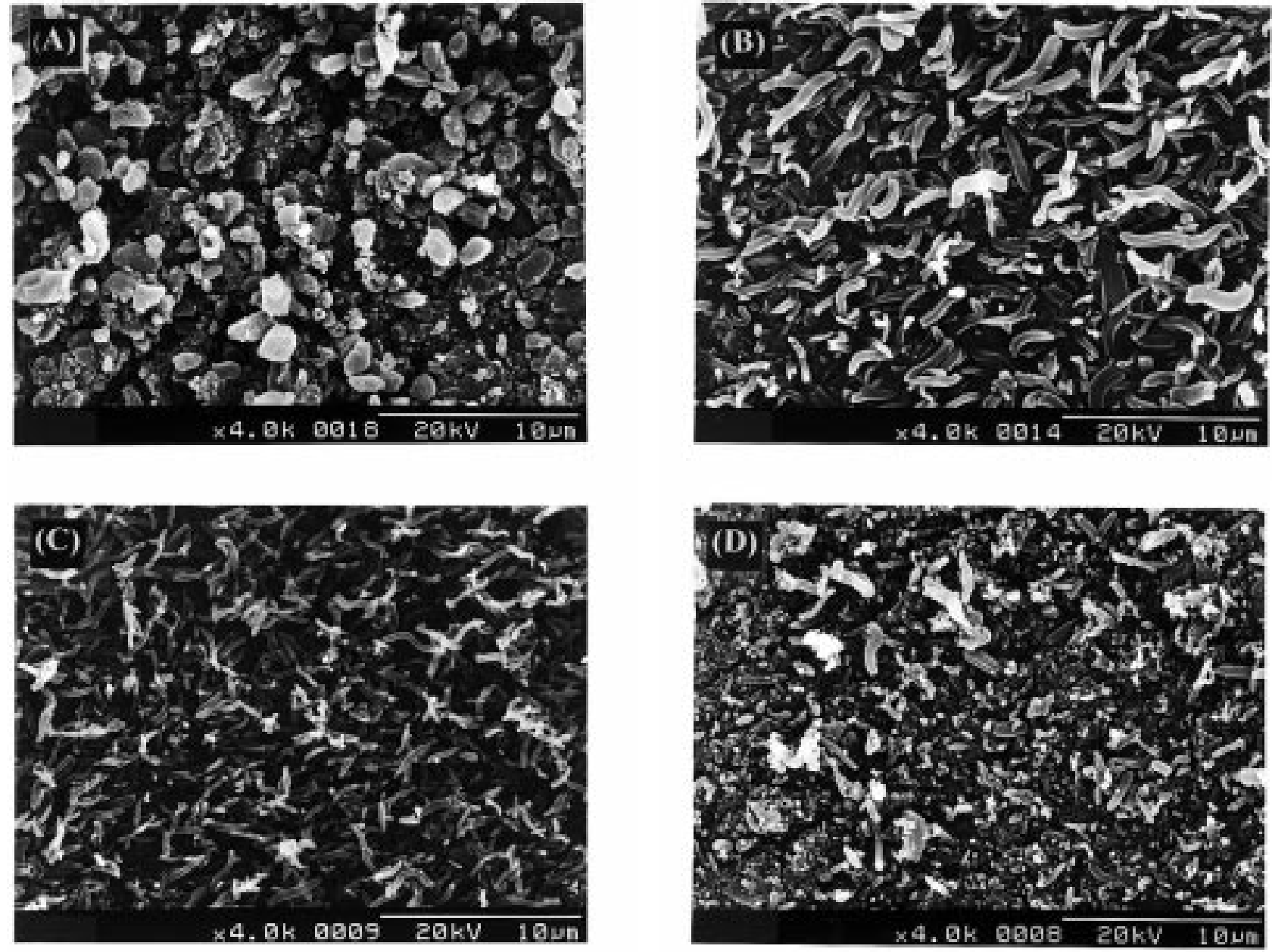

Figure 3. Scanning electron micrograph showing the morphology of $C_{16} T M A B$-aluminosilicate system with different water content. The samples are the same as in Figure 2, with Figure $3 \mathrm{X}$ corresponding to Figure $2 \mathrm{X}$.

the tubular morphology. Comparing the amounts of the salts needed to aid the production of tubular structure, the order follows the sequence $\mathrm{KNO}_{3}<\mathrm{NaBr}<\mathrm{NaCl}$ $\sim \mathrm{NaCl} \sim \mathrm{K}_{2} \mathrm{SO}_{4} \sim \mathrm{Na}_{2} \mathrm{SO}_{3}$ or $\mathrm{CH}_{3} \mathrm{COONa}{ }^{33,34}$ It might be due to that $\mathrm{NO}_{3}^{-}$and $\mathrm{Br}^{-}$anions have greater affinity for combining with micelle of the $C_{16} T M A B$ to promote the formation of the complex surfactant structure than other counterions. ${ }^{33,34}$ These results suggest that the addition of salts can provide another method in tailor-making the morphol ogy of MCM-41 materials. Nevertheless, it must be noted that the amount of the salts added should be in a suitable range for the coexistence of lamellar and hexagonal intermediate membrane phases in order to obtain the tubular morphology. Adding too much of the salts into an appropriate composition for the preparation tubular morphology MCM-41 materials would lead to a high viscosity reaction solution and destroy the tubule morphology.

Temperature. It has been known that liquid-crystal phases of surfactants are critically dependent on temperature. ${ }^{32}$ The temperature of the reaction system therefore would be a key factor in determining the morphology of MCM-41 samples. Figure 5 displays the SEM micrographs of MCM-41 materials synthesized

(33) Dorshow, J .; van Biggs, R. B.; Bunton, C. A.; Nicoll, D. F. J Phys. Chem. 1983, 87, 1409. 5540. with the same composition under various temperature. At $20{ }^{\circ} \mathrm{C}$, the morphology of the MCM-41 product was in plate form (Figure $5 A$ ). This implies that $C_{16} T M A B$ is apt to form lamellar type liquid crystals at low temperature, which direct the morphology of the silicate product. As the temperature was raised to $30{ }^{\circ} \mathrm{C}$, the morphology of the MCM-41 product was exclusively in tubular form. The $\mathrm{C}_{16} \mathrm{TMAB}$-aluminosilicate system at this temperature probably favors the formation of mixture of lamellar-hexagonal phase, which was necessary for the formation of the tubular structure. But the morphol ogy of the MCM-41 materials was degraded to particular particles when the temperature is further raised to $40{ }^{\circ} \mathrm{C}$. This probably means that high temperature would destroy the formation of layers of the surfactant/silicates, which was necessary in the formation of the tubular structure.

All these results in the previous three sections emphasize that the coexistence of a suitable amount of water layer and layer of the surfactant/silicates, which gives the membrane-like intermediate of hexagonalarrayed rod micelles, would be a necessary condition for preparing the tubular MCM-41 materials.

Si/Al Ratio. In the formation of tubular MCM-41 materials, the soft intermediate membrane layer in suitable dimension is necessary. It has been reported that the incorporation of aluminum into the structure 
(A)

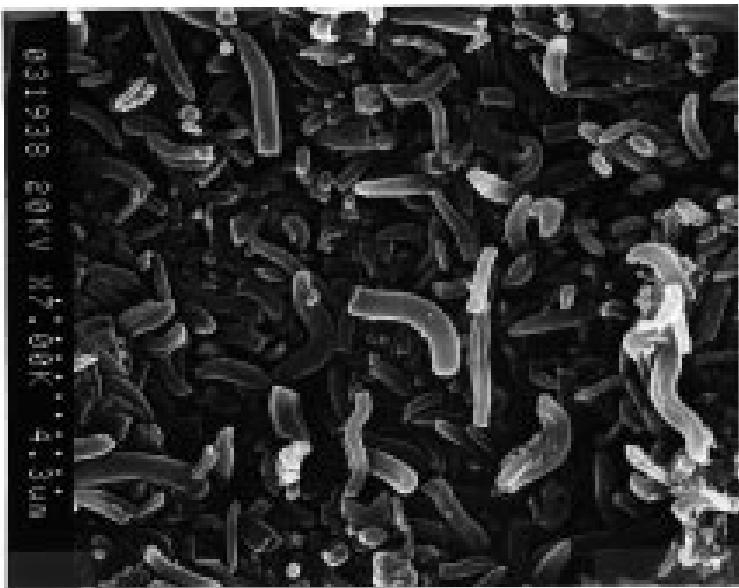

(B)

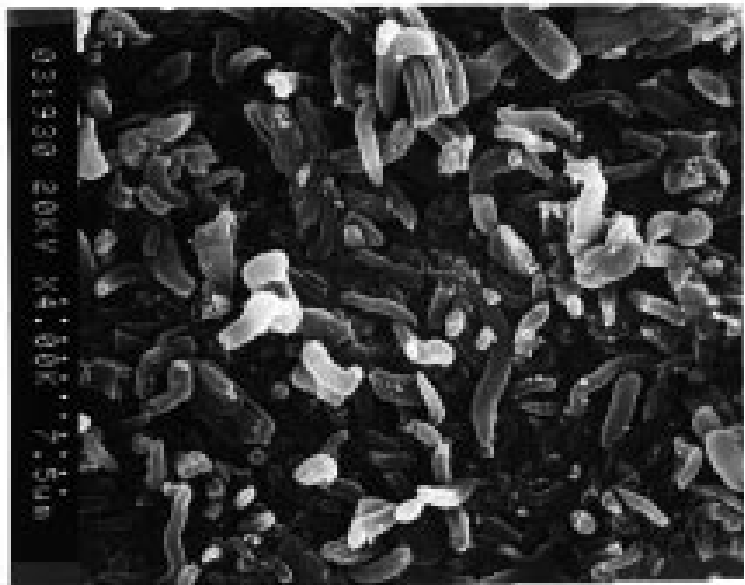

Figure 4. Scanning electron micrographs of the aluminosilicate MCM-41 materials synthesized from water/surfactant ratio $=189$ under the condition of adding different salts: $(A)$ addition of $\mathrm{KNO}_{3}\left(\mathrm{KNO}_{3} / \mathrm{C}_{16} \mathrm{TMAB}=0.12\right)$, (B) addition of $\mathrm{NaBr}\left(\mathrm{NaBr} / \mathrm{C}_{16} \mathrm{TMAB}=0.16\right)$.

can reduced the MCM-41 crystal size..$^{35}$ In the case of $\mathrm{C}_{16} \mathrm{TMAB}$-aluminosilicate, this effect is also reflected in the size of tubular structure. Figure 6 shows the morphology of the MCM-41 materials synthesized with different Si/Al ratio. Under the pure silica condition, the MCM -41 materials has about only $10 \%$ products in large tubular structure and the rest are in microparticle form (Figure 6A). This may be due to the membrane intermediate is thicker and more rigid that could only be bent into larger tubular structure with difficulties. With the Si/Al ratio at about 25 , the morphology of the MCM-41 product was uniform in shorter and thinner tubular form (Figure 6B). In the incorporation of al uminum into the framework, the size of the intermediate liquid crystal becomes smaller and leads to the formation of a smaller and uniform tubule. ${ }^{35}$ At further decreasing of the Si/Al ratio, the intermediate would further decrease to smaller size until the tubules can no longer form. Again, the percentage of MCM-41 materials with tubular structure decreases (Figure 6C). The morphology of MCM-41 product finally completely transforms to particulate form at $\mathrm{Si} / \mathrm{Al}$ below 10 (Figure 6D).

(35) Luan, Z.; He, H.; Zhou, W.; Cheng, C.-F .; Klinowski, J . J . Chem. Soc., Faraday Trans. 1995, 91, 2955.
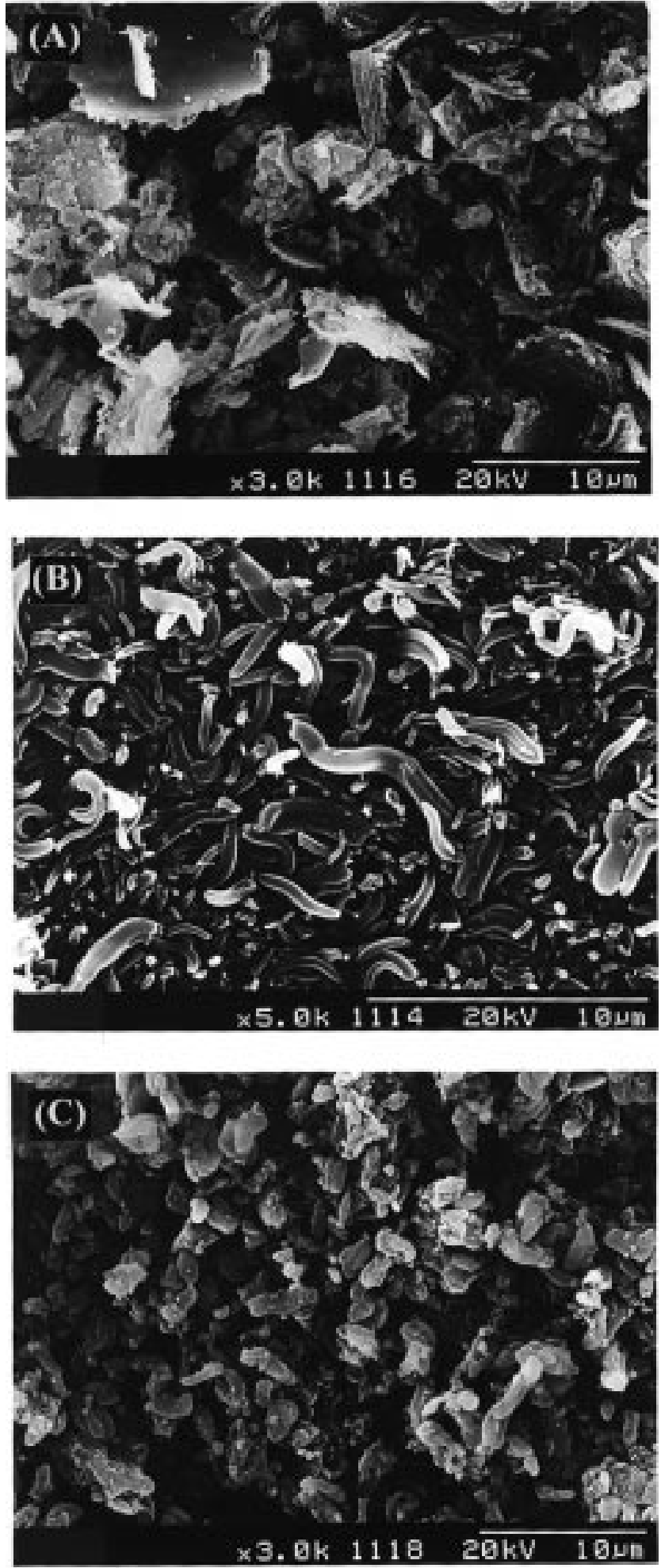

Figure 5. Scanning electron micrographs of the aluminosilicate MCM-41 materials synthesized at different temperature. The gel composition $1 \mathrm{SiO}_{2}: 0.014 \mathrm{Al}_{2} \mathrm{O}_{3}: 0.39 \mathrm{Na}_{2} \mathrm{O}: 0.48 \mathrm{C}_{16}$ TAB:0.29 $\mathrm{H}_{2} \mathrm{SO}_{4}: 82.6 \mathrm{H}_{2} \mathrm{O}$ : (A) $20{ }^{\circ} \mathrm{C}$, (B) $30{ }^{\circ} \mathrm{C}$, (C) $40{ }^{\circ} \mathrm{C}$.

Incorporation of aluminum into framework of the MCM-41 not only affects the morphology but also lowers the crystallinity. Figure 7 show that the main peaks characteristic of MCM-41 become broader and less intense with decrease of Si/Al ratio. The relatively poor arrangement of the hexagonal pattern with lower $\mathrm{Si} / \mathrm{Al}$ ratio is probably due to the distortion of the long-range 

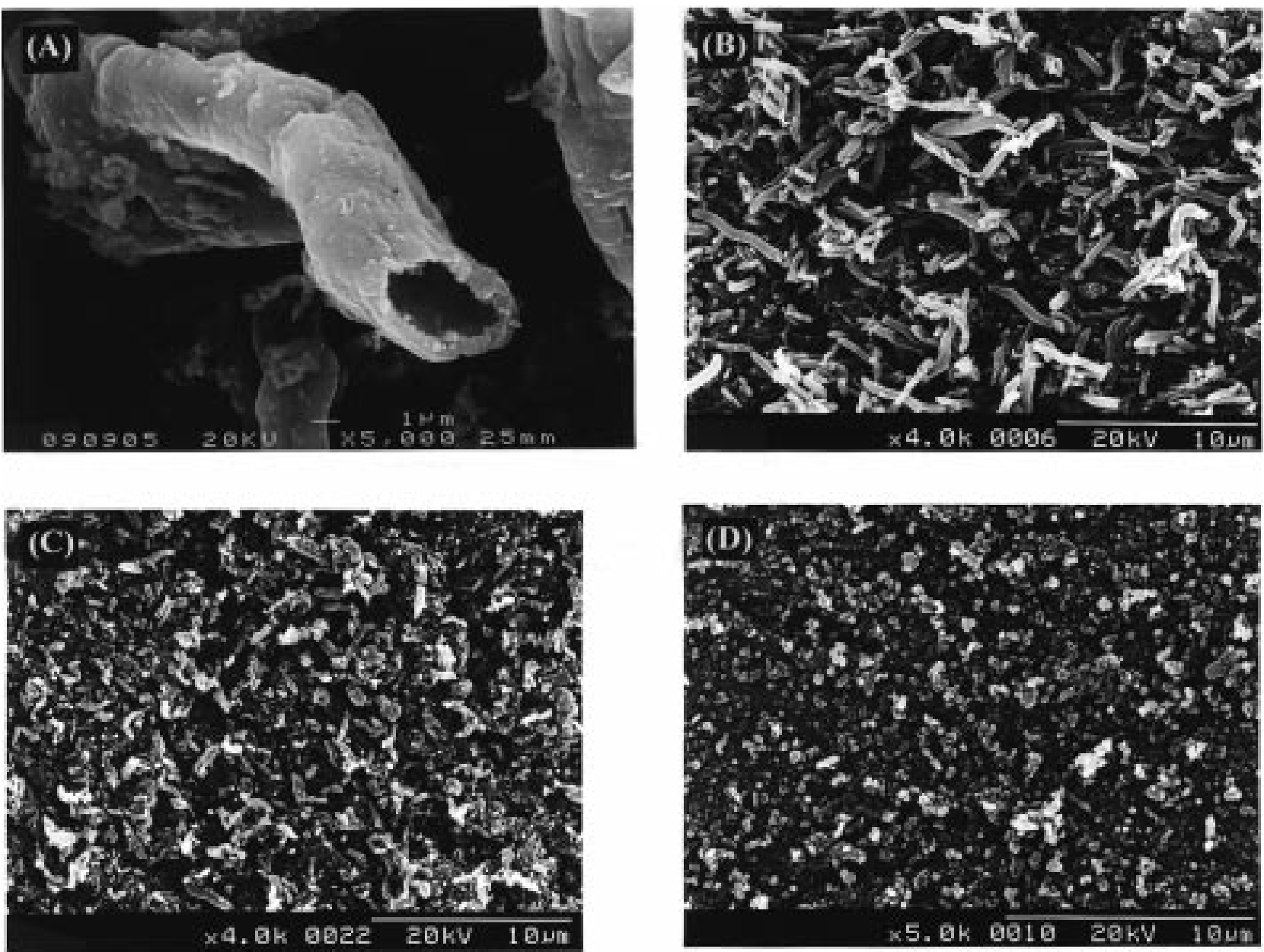

Figure 6. Scanning electron micrographs of the mophology of the aluminosilicate MCM-41 materials prepared from different $\mathrm{Si} / \mathrm{Al}$ ratio. (A) $\mathrm{Si} / \mathrm{Al}=\infty$, (B) $\mathrm{Si} / \mathrm{Al}=25,(\mathrm{C}) \mathrm{Si} / \mathrm{Al}=15.2$, (D) $\mathrm{Si} / \mathrm{Al}=9.5$.

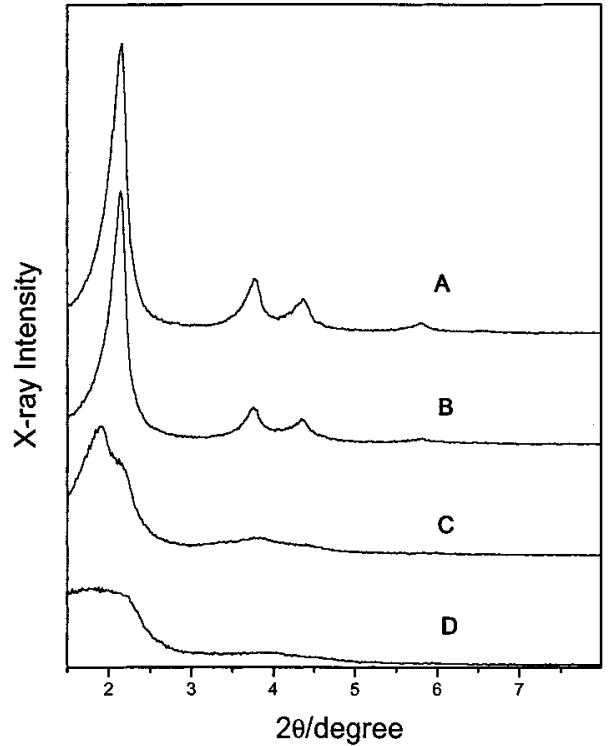

Figure 7. Powder X-ray diffraction patterns of the MCM-41 materials prepared from different Si/AI ratio: (A) $\mathrm{Si} / \mathrm{Al}=\infty$, (B) $\mathrm{Si} / \mathrm{Al}=25$, (C) Si/Al $=15.2$, (D) $\mathrm{Si} / \mathrm{Al}=9.5$.

ordering of the mesoporous structure and defective hexagonal arrays. Moreover, ${ }^{27} \mathrm{AI}$ MAS NMR spectroscopes of these samples show peaks near 52 ppm, which indicates that all of the aluminum remains in the framework. ${ }^{36,37}$
When the aluminum sulfate was used as the source of the aluminum, the MCM-41 products of $\mathrm{C}_{16} \mathrm{TMAB}-$ aluminosilicate was only in the microparticle form without tubular structure. This may be a result that the aluminum sulfate is an acid aluminum source. Thus the faster silica condensation would result in an alumi nosilicate intermediate with too rigid structure to bend into tubular morphology. Thus, sodium aluminate is a more suitable aluminum source, which keeps the reaction system in highly alkaline condition to have a less-condensed aluminosilicate intermediate for producing the tubular structure.

Stirring Rate. We al so tried to synthesize the MCM41 with tubular morphology at different stirring rate. Under normal rates, the sample morphology was almost in the same tubular structure. The results reveal that stirring rate does not have a strong influence on the morphology of the MCM-41 products. It supported that the tubular structure was formed from the phase transition process induced by chemical reaction. This is different from that of Schacht et al., where the hierarchical structure was formed at the oil-water interface and changed with the stirring rate. ${ }^{17}$

Counterion Effect. SEM photographs show that the as-synthesized samples prepared with $\mathrm{C}_{16} \mathrm{TMACl}$ is

(36) Tuel, A.; Gontier, S. Chem. Mater. 1996, 8, 114.

(37) Busio, M.; J änchen, J .; van Hoof, J . H. C. Microporous Mater. 1995, 5, 211. 


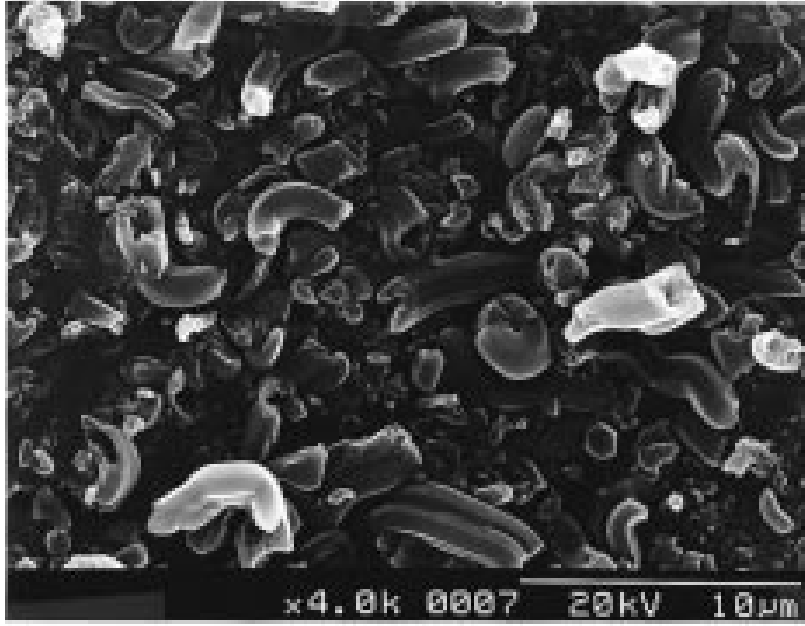

Figure 8. Scanning electron micrographs of the morphology of the pure silica MCM-41 materials prepared from $\mathrm{C}_{16^{-}}$ $\mathrm{TMACl}$-silicate system. The mole ratio of the gel is $1 \mathrm{SiO}_{2}$ : $0.39 \mathrm{Na}_{2} \mathrm{O}: 0.29 \mathrm{H}_{2} \mathrm{SO}_{4}: 0.48 \mathrm{C}_{16} \mathrm{TACl}: 73.7 \mathrm{H}_{2} \mathrm{O}$.

also in the tubular morphology (Figure 8). The diameters are rather uniform and the yield is high. The diameter of the tubule is about $1.0 \mu \mathrm{m}$, and the average length is roughly $3.6 \mu \mathrm{m}$. In the micrographs, some head-broken tubules reveal that the tubules are hollow and the wall thickness of the tubules is about $0.20 \mu \mathrm{m}$. Besides, both the as-synthesized sample prior to hydrothermal reaction and the calcined product show the same tubular structures. These results indicate that the tubular morphology is formed during the process of neutralization, and these tubular structures are stable through hydrothermal reaction and calcination. On the basis of the SEM micrographs, more than $70 \%$ of the particles in these samples are in tubular form. The rest are in microparticle morphology.

To show that all the tubules are indeed hollow, we present transmission electron micrographs (TEM) of the calcined samples of $\mathrm{C}_{16} \mathrm{TMACl}$ (Figure $9 \mathrm{~A}$ ) first at low magnification $(\times 6000)$. We see pictures of hollow tubules with dark edges. In fact all the tubules in Figure $9 \mathrm{~A}$ are hollow. Figure 9B is in higher magnification of a single tubule. It reveals equidistant parallel lines, along the tubular axis, with apparent average spacing of imagine around $3.70 \mathrm{~nm}$. This result is consistent with the XRD result $(\mathrm{d}$ spacing $=3.90 \mathrm{~nm}) .38$ From the TEM micrograph, we also found that the darkness of the parallel lines is not uniform. There are defects, probably due to slitlike pore resulting in the outgassing of water vapor in hydrothermal reaction.

The calcined product of $\mathrm{C}_{16} \mathrm{TMACl}$ was further characterized by measuring its $\mathrm{N}_{2}$ adsorption-desorption isotherm (not shown here). The sample has a BET surface area around $1000 \mathrm{~m}^{2} / \mathrm{g}$ and a narrow pore size distribution. The average pore diameter is about 2.80 $\mathrm{nm}$ and half-height width of the pore diameter distribution is approximate $0.20 \mathrm{~nm}$. In addition to the steep increase in adsorbed volume at $\mathrm{p} / \mathrm{p}_{0} \approx 0.36$, there is a hysteresis covering a wide range at $\mathrm{p} / \mathrm{p}_{0}>0.5$ in the isotherm. The shape of this hysteresis indicates that they are likely due to the slit-shaped pores in imperfect packing, as can be seen in TEM micrographs.

(38) Chenite, A.; Page, Y. L.; Sayari, A. Chem. Mater. 1995, 7, 1015.
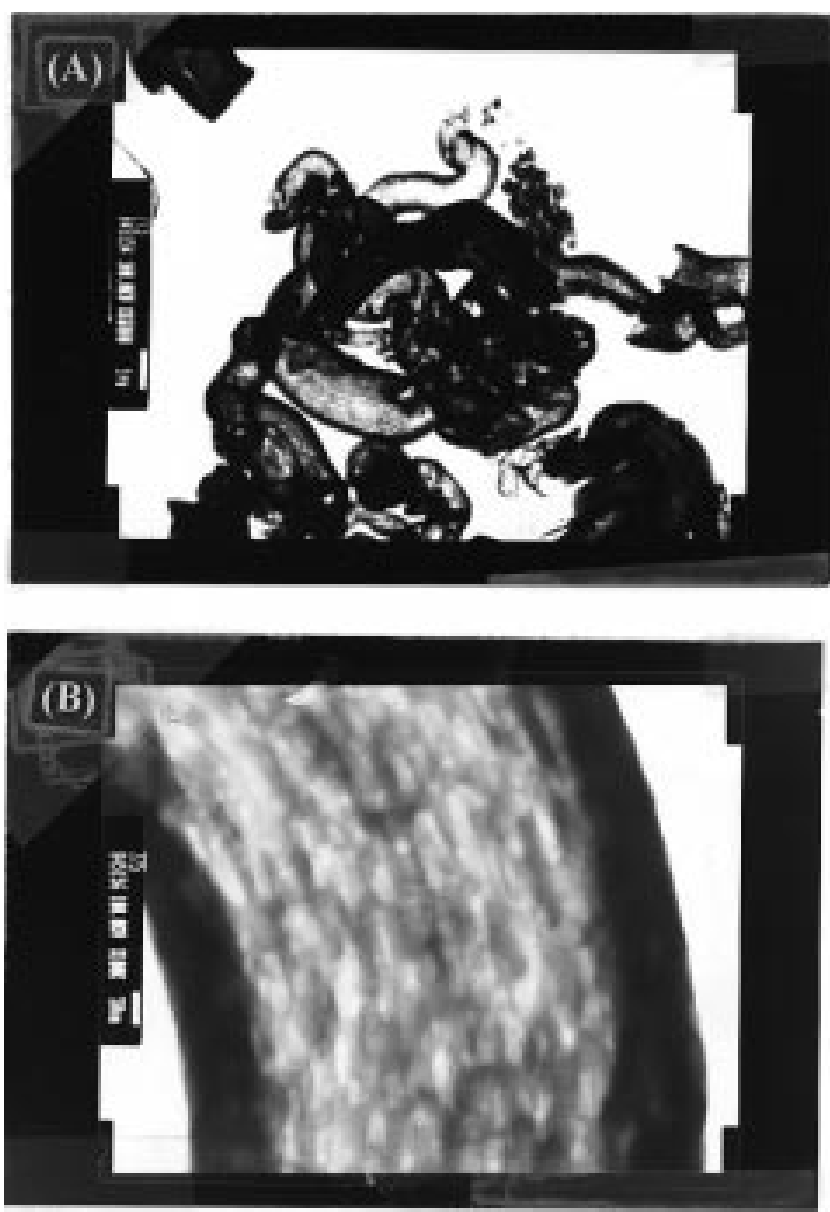

Figure 9. Transmission electron micrograph of the assynthesized tubular MCM-41 material of Sample 8. (A) $\times 6000$, scale bar is $1 \mathrm{~m}$; (B) $\times 100000$, scale bar is $50 \mathrm{~nm}$.

To study the formation mechanism of MCM-41, the gel mixture of silicate and $\mathrm{C}_{16} \mathrm{TMACl}$ isolated at different stages of neutralization and the solid product after hydrothermal reaction were examined by XRD. When the solution of $\mathrm{C}_{16} \mathrm{TMACl}$ was mixed with sodium silicate, a clear low-viscosity solution was formed. ${ }^{39}$ During the acidification procedure, this clear mixture first undergoes a phase separation, the upper phase is a surfactant-rich viscous gel whose XRD pattern is associated with a layered mesostructure as shown in Figure 10A. Upon further addition of the acid, a precipitate forms which has an XRD pattern of preponderous hexagonal mesostructure and a little lamellar phase (Figure 10B). After complete addition of the acid, a solid product with four well-defined XRD peaks in $2 \theta$ $=1.5-6^{\circ}$ region $(\mathrm{d}$ spacing $=3.91 \mathrm{~nm})$ is obtained indicating the formation of MCM-41. After hydrothermal reaction, the material shows a more distinct $X R D$ pattern of MCM-41 (Figure 10C). Calcination causes the $d$ spacing to shrink about $0.2 \mathrm{~nm}$, but four XRD peaks still retain (Figure 10D). The very little lattice contraction and structural integrity indicate that the nanostructure of the sample prepared by this new process is very stable. 6202.

39) Lee, Y. S.; Surjadi, D.; Rathman, J . F. Langmuir 1996, 12, 


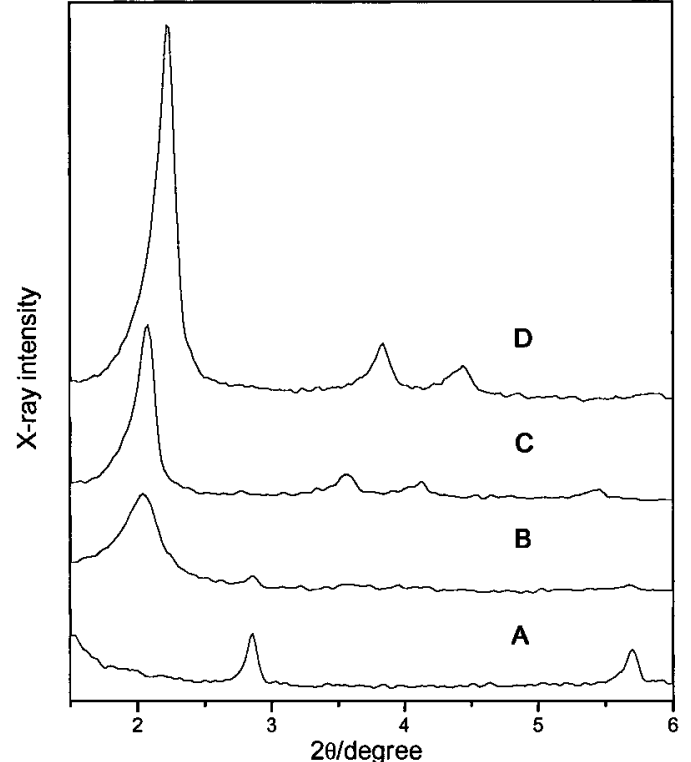

Figure 10. Powder X-ray diffraction patterns of mesostructure precipitated from the same mixture with mole ratio, 1 $\mathrm{SiO}_{2}: 0.39 \mathrm{Na}_{2} \mathrm{O}: 0.48 \mathrm{C}_{16} \mathrm{TACl}: 73.7 \mathrm{H}_{2} \mathrm{O}: \mathrm{x} \mathrm{H}_{2} \mathrm{SO}_{4}$ at various stages of synthesis. (A) As-synthesized at room temperature with $x=0.1$, (B) $x=0.19$, (C) after complete addition of acid $x=0.29$, (D) after calcination of sample $C$.

The formation mechanism of MCM-41 using $\mathrm{C}_{16^{-}}$ $\mathrm{TMACl}$, through a lamellar mesostructure to the hexagonal mesopore by gradual acidification, is similar to that observed by Monnier. ${ }^{11}$ But when $\mathrm{C}_{16}$ TMAB was used as the surfactant instead, the formation mechanism was different, in which the XRD data show that the hexagonal structure was formed immediately after the acidification procedure, and the mechanism is akin to that proposed by Chen et al. ${ }^{40}$ That is, hexagonal structures are directly assembled from cylindrical micelles. These results demonstrate that the counterion of the surfactant has a significant influence on the formation pathway of MCM-41 materials.

The high yield of the silicate of hollow tubules in uniform size obtained in mild solution condition lead us to propose a "liquid-crystal phase transformation" mechanism similar to that proposed for $\mathrm{C}_{16} \mathrm{TMAB}-$ aluminosilicate system previously. ${ }^{26}$ Before neutralization, the high $\mathrm{pH}$ condition ensures silicates to be mainly in the form of monomers or low oligomers and have little energetic advantage to access the cationic headgroup of surfactant; therefore, an almost clear solution of spherical micelles of $\mathrm{C}_{16} \mathrm{TMACl}$ was obtained. When a small amount of the acid is added, silicate monomers condense to form silica polyanions which then act as multidentate ligands and combine with $\mathrm{C}_{16^{-}}$ $\mathrm{TMA}^{+}$strongly to form a surfactant-rich lamellar membrane phase, with water layers distributed between membrane layers, which is the supernatant of the solution. Notice that, in ref 26 , our previous $C_{16} T M A B /$ aluminosilicate system results in membrane layers consisting of hexagonal micelle cylinders at this stage. With further acidification, the negative charges of the

(40) Chen, C. Y.; Burkett, S. L.; Lin, H. X.; Davis, M. E. Microporous Mater. 1993, 2, 27. (b) Chen, C. Y.; Li, H. X.; Davis, M. E. Microporous Mater. 1993, 2, 17. (c) Chen, C. Y.; Xiao, S. Q.; Davis, M. E. Microporous Mater. 1995, 4, 1.
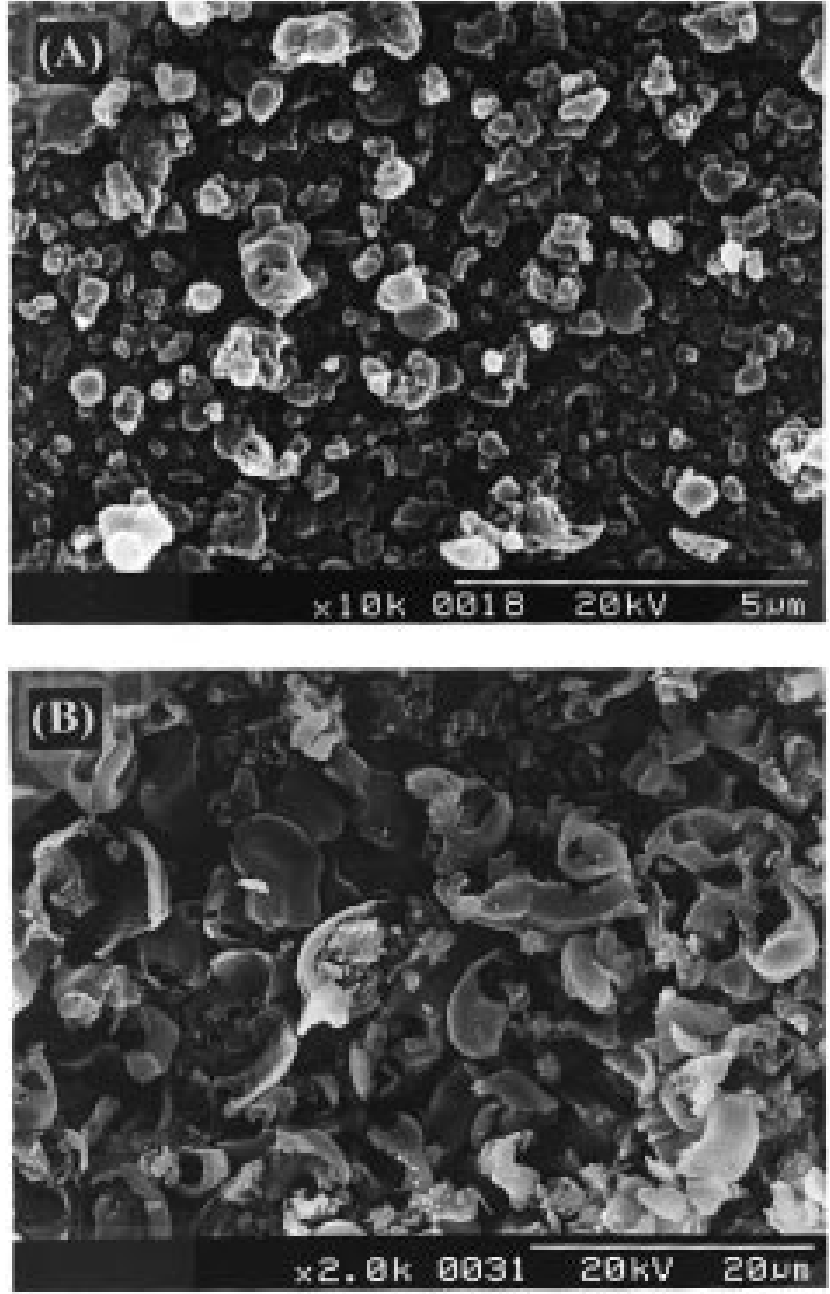

Figure 11. Scanning electron micrographs of as-synthesized products of pure silica MCM-41 prepared from different surfactants: (A) $C_{12} T M A B$, (B) $C_{14} T M A B$.

silicate anions are neutralized, therefore, the shielding effect of the anions decreases. As a result, the transformation of the lamellar phase to hexagonal mesostructure takes place. As the membrane curls into microtubules, the process is proposed to occur first at the interface of surfactant-rich lamellar phase and aqueous solution. Thethickening of silicates and charge imbalance on the outer layers of the surfactant-rich lamellar phase would force the membrane to curl up as microtubules. The complete addition of the acid would transform the lamellar mesostructure completely to tubular hexagonal mesoporous MCM-41.

Effect of Surfactant Carbon Chain. The same synthesis procedure was also carried out to prepare pure-silica MCM-41 materials with other surfactants, such as $C_{14} T M A B$ and $C_{12} T M A B$. The products with $\mathrm{C}_{12} \mathrm{TMAB}$ are in microparticles (Figure $11 \mathrm{~A}$ ). On the other hand, there are many broken hollow tubule and particle in the $\mathrm{C}_{14} \mathrm{TMAB}$ product (Figure 11B). These results show that carbon chain length of the surfactant is al so important in affecting the morphology of MCM41 materials obtained. The interaction between ol igomeric silica polyanions and the surfactant micelles is in parallel with that of system of cationic surfactant and anionic polyelectrolyte, ${ }^{41,42}$ the surfactant of shorter chain length has a less affinity with the polyanionic species. This explains why phase-separated intermedi- 
Table 1. Morphology Patterns of MCM-41 for Various Combinations of Surfactants and Condensation Species

\begin{tabular}{|c|c|c|}
\hline \multirow[b]{2}{*}{ surfactants } & \multicolumn{2}{|c|}{ condensation species } \\
\hline & pure silica & aluminosilicate \\
\hline $\begin{array}{l}\mathrm{C}_{16} \mathrm{TMACl} \\
\mathrm{C}_{16} \mathrm{TMAB}\end{array}$ & $\begin{array}{l}\text { thin tubules, high yield } \\
\text { thick tubules, low yield }\end{array}$ & $\begin{array}{c}\text { microparticles } \\
\text { thin tubules, } \\
\text { high yield }\end{array}$ \\
\hline $\mathrm{C}_{14} \mathrm{TMAB}$ & $\begin{array}{l}\text { broken half-tubules, } \\
\text { high yield }\end{array}$ & microparticles \\
\hline $\mathrm{C}_{12} \mathrm{TMAB}$ & microparticles & microparticles \\
\hline
\end{tabular}

ate is not observed in $\mathrm{C}_{12} \mathrm{TMAB}$-silicate system, and there are only microparticles formed in $\mathrm{C}_{12} \mathrm{TMAB}$ product. The behavior of $\mathrm{C}_{14} \mathrm{TMAB}$-silicate is somewhat intermediate in the process of acidification, thus the $\mathrm{C}_{14} \mathrm{TMAB}$ product has both the broken hollow microtubules and microparticles. By surveying through different surfactants, the formation of the hollow microtubule of pure silica MCM-41 was determined to be most suitable with the surfactant with carbon chain length of 16.

When aluminate source was added to synthesize aluminosilicate form of MCM-41, the morphology of the products became microparticles for all the surfactants except for $\mathrm{C}_{16} \mathrm{TMAB}$. We, somewhat roughly, designate hollow tubules as thin or thick by their diameter less or greater than $1 \mu \mathrm{m}$. And we speak of high yield as hollow tubules represent more than $50 \%$ of the products. We summarize the morphol ogy patterns of MCM-41 for various combinations of surfactants and condensation species in Table 1.

In Table 1 , the upper left corner $\left(\mathrm{C}_{16} \mathrm{TMACl}\right)$ represents the strongest tendency to form lamellar patterns before it curls into microtubules. As the chain length decreases or the counterion becomes more associating, it forms a hexagonal structure more easily instead of lamellar ones. As shown in Figure 10, and in ref 26, microtubules form in the transition boundary between these two different behaviors, lamellar and hexagonal arrangements.

We see, from Table 1, that starting from $\mathrm{C}_{16} \mathrm{TMAB}$ by either substituting chloride counterion or adding

(41) Thalberg, K.; Lindam, B.; Karlström, G. J . Phys. Chem. 1990, 94, 4289.

(42) Thalberg, K.; Lindam, B. J . Phys. Chem. 1991, 95, 3370. aluminate makes the hollow tubules thinner. Both would give an easier-to-bend membrane to yield higher percentage of thin microtubules (see $\mathrm{C}_{16} \mathrm{TMACl}$ and $\mathrm{C}_{16^{-}}$ TMAB). As chain length decreases, it tends to form microparticles. $\mathrm{C}_{14} \mathrm{TMAB}$ represents the intermediate case where its condensation with pure silica would give broken half-tubules (Figure 11B), e.g., failed microtubules.

The various organizations and their causes are rich, as summarized in Table 1. Further works are needed to evaluate and rationalize the structure/mechanism relationship of these novel structures.

\section{Conclusions}

In conclusion, we have designed a new procedure to produce alumi nosilica holl ow microtubules of MCM-41 that is formed from a soft layered phase constructed of mesostructures of self-organization of surfactant and silica polyanionic oligomers to the complex hierarchical tubules-within-tubule order of MCM-41 through a liquidcrystal phase transformation. The formation of this novel tubular morphology is sensitive to the reactant compositions and synthesis procedure. This gives one a new approach to explore many rich complex structures that are possible in the surfactant-aluminosilicate system and to form new zeolite structures. The hollow tubular structure we found here is very similar to the siliceous skeletons of marine diatoms and radiolaria. ${ }^{43}$ The liquid-crystal phase transformation mechanism proposed in this report could provide a new way toward understanding high-order biominerization. 44,45 The ability to synthetically control the intricate hol low tubuleswithin-tubule morphol ogy of aluminosilicates could find important application in nanotechnology. One could further explore the possibility of multifunctional material with such kind of hierarchical organization.

Acknowledgment. This research was supported by National Science Council of Taiwan (NSC 85-2113-31-M-002-032cc).

\section{CM9705754}

(43) Burekle, L. H. Introduction to Marine Micropal eontology; Haq, B. U., Boersn, A., Eds.; Elsevier Press: New York, 1978.

(44) Ozin, G. A. Acc. Chem. Res. 1997, 30, 17

(45) Mann, S. J . Chem. Soc., Dalton Trans. 1993, 1. 